\title{
Experimental Study of Heat Transfer Enhancement through a Tube with Wire-Coil Inserts at Low Turbulent Reynolds Number
}

\author{
Mohammad Zoynal Abedin and M. A. Rashid Sarkar
}

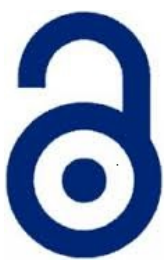

Received: 30 April 2018

Accepted: 21 June 2018

Published: 15 September 2018

Publisher: Deer Hill Publications

(c) 2018 The Author(s)

Creative Commons: CC BY 4.0

\begin{abstract}
This paper reports an experimental analysis to investigate the enhancement of turbulent heat transfer flow of air through one smooth tube and four different tubes with wire-coil inserts (Pitches, $P_{c}=12,24,40$, and $50 \mathrm{~mm}$ with corresponding helix angles, $\alpha=10^{\circ}, 20^{\circ}, 35^{\circ}$, and $45^{\circ}$, respectively) at low Reynolds numbers ranging from 6000 to 22000. The test section of the tube was electrically heated and was cooled by fully developed turbulent air flow. The performance of the tubes was evaluated by considering the condition of maximizing heat transfer rate. From the measured data, the heat transfer characteristics such as heat transfer coefficient, effectiveness and Nusselt number, and the fluid flow behaviours such as friction factor, pressure drops and pumping power along the axial distance of the test section were analyzed at those Reynolds numbers for the tubes. The results indicated that for the tubes with wirecoil inserts at low Reynolds numbers, the turbulent heat transfer coefficient might be as much as two-folds higher, the friction factors could be as much as four-folds higher, and the effectiveness might be as much as 1.25 folds higher than those for the smooth tube with similar flow conditions. A correlation was also developed to predict the turbulent heat transfer coefficients through the tubes at low Reynolds numbers.
\end{abstract}

Keywords: Heat transfer enhancement, Wire-coil inserts, Low Reynolds number, Friction factor, Effectiveness.

\section{NOMENCLATURE}

$c_{p} \quad$ specific heat at constant pressure, $\mathrm{kJ} /(\mathrm{kg} \mathrm{K})$

$d_{w} \quad$ diameter of wire coil, $\mathrm{m}$

$D_{i} \quad$ inside diameter of tube, $\mathrm{m}$

$e \quad$ effectiveness of the exchanger

$F_{i} \quad$ fanning friction factor, $\left[\left\{(-\Delta P / X) D_{i j}\right\} /\left(2 \rho V^{2}\right)\right]$

$h$ convective heat transfer coefficient, $W /\left(\mathrm{m}^{2} \mathrm{~K}\right)$

$k$ thermal conductivity, $\mathrm{W} /(\mathrm{m} \mathrm{K})$

$L \quad$ length of the test section, $m$

$\mathrm{Nu} \quad$ Nusselt number, $h D_{i} / k$

$P \quad$ pressure, $\mathrm{Pa}$

$P_{c} \quad$ pitch of the coil, $\mathrm{mm}$

$P_{m} \quad$ pumping power, $W$

$\operatorname{Pr} \quad$ Prandtl number, $\mu c_{p} / k$

Re Reynolds number, $V D_{i} / v$

$T_{b} \quad$ bulk temperature of air, ${ }^{\circ} \mathrm{C}$

$T_{w} \quad$ wall and coil surface temperature, ${ }^{\circ} \mathrm{C}$

\author{
M. Z. Abedin ${ }^{1} \otimes$ and M. A. R. Sarkar ${ }^{2}$ \\ 'Department of Mechanical Engineering \\ Dhaka University of Engineering and Technology \\ Gazipur 1700, Bangladesh \\ E-mail: abedin.mzoynal@duet.ac.bd \\ 2Department of Mechanical Engineering \\ Bangladesh University of Engineering and Technology \\ Dhaka 1000, Bangladesh \\ E-mail: rashid@me.buet.ac.bd
}

Reference: Abedin, M. Z. and Sarkar, M. A. R. (2018). Experimental Study of Heat Transfer Enhancement through a Tube with WireCoil Inserts at Low Turbulent Reynolds Number. International Journal of Engineering Materials and Manufacture, 3(3), 122-133. 


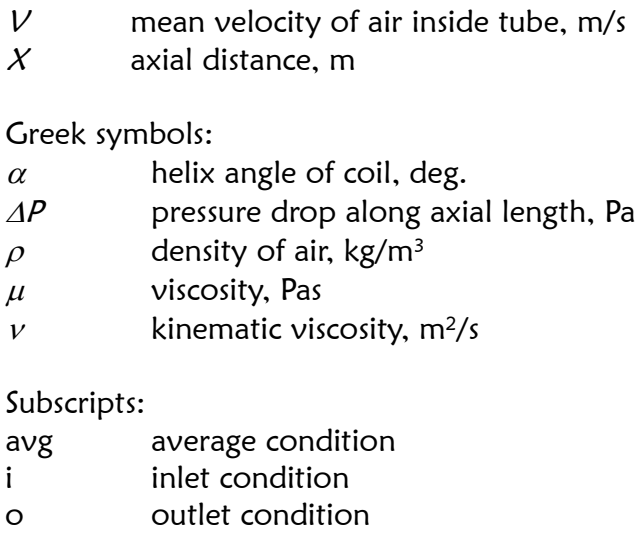

\section{INTRODUCTION}

Heat transfer enhancement is of very importance considering its practical applications in many engineering and environmental fields. Therefore, an increasing trend of conducting research about the concept of enchantment has received a tremendous attention of many scientists and engineers in the fast few decades [1]. Especially, in the processes of industrial applications, heat exchangers are found to be responsible for transferring more than $80 \%$ of energy which emphasizes the importance of heat transfer enhancement [2]. Generally, three main categories are considered for the enhancement techniques. The first one is called the active method which involves some external power to achieve the desired flow condition and the method is rarely used in the practical design applications due to its complexity in providing the external power in many applications. The second one is the passive method which does not require external power, but sometimes, the additional power is originated from the power of the fluid motion in the cases of the tubes with insert devices. The third one is the compound method consisting of both active and passive methods and the method has limited applications due to its complex design procedures [3]. The compound method mostly deals with the passive method that leads to have wide applications in many engineering fields such as in the heat recovery processes, refrigeration and air conditioning systems and dairy processes.

In case of passive method in a tube with different inserts, the mechanism introduces some swirls into the flow field and produces periodic redevelopment of the boundary layer that increases the turbulence intensity, and finally enhances the effective heat transfer rate [4]. Among the enhancement techniques, the tube with wire coil inserts is considered to be the superior due to its lower cost, easy installation, and unchanged original smooth tube mechanical strength [5]. The heat transfer enhancement for servotherm medium-grade oil in a laminar flow through one smooth tube and seven wire-coils inserted tubes of varying wire diameter and pitch of wire coil was experimentally investigated by Uttarwar and Rao [6]. In their studies, it was revealed for wire-coil inserted tubes that as much as $350 \%$ heat transfer enhancement might be found and as much as $80 \%$ reduction in heat-exchanger area could be achieved by considering the pumping power and basic geometry as constant. For the heat transfer enhancement, many augmentation techniques have been developed and made practicable with a significant heat transfer improvement. For instances, the heat transfer enhancement in the heat-exchanger tubes could be achieved not only with internal fin [7-9], twisted-tape inserts [10-18], metallic filament inserts [19], brush inserts [20], longitudinal strip inserts [21], but also with internal roughness [22], and so on. On the other hand, some numerical investigations were conducted for the predictions of fluid flow behaviours and heat transfer through tubes with fins [23-26].

The experimental investigations on turbulent flow heat transfer and fluid friction in a $25 \mathrm{~mm}$ inner diameter copper tube, tightly fitted with helical wire-coil inserts of varying pitch and wire diameter were carried out by Sethumadhavan and Rao [27]. Recently, Vahidifar and Kahrom [28] experimentally studied the heat transfer enhancement in a heated tube caused by wire-coil and rings, and found that the overall enhancement efficiency increased as much as $128 \%$. Garcia et al. [29] also investigated the heat transfer enhancement for the laminar and transitional flow in the wire coil inserted tubes. Sarkar et al. [30] experimentally investigated the heat transfer enhancement in turbulent flow through the tubes with wire-coil inserts with varying pitches. In their studies, it was revealed that as much as two-fold heat transfer improvement might be found and as much as four-fold friction factor could be achieved for wire-coil inserted tubes for various flows having Reynolds numbers ranging from 20000 to 45000. Although the heat transfer enhancement both in laminar and turbulent flows with various augmentation techniques have been clarified to some extent, no approach of the experimental investigations for the improvement of heat transfer coefficients through a tube with wire-coil inserts at low Reynolds numbers has so far been reported. Therefore, in the present study, we have investigated experimentally the heat transfer enhancement in a turbulent air flow through one smooth tube and four wire-coil inserted tubes at low Reynolds numbers ranging from 6000 to 22000 . 


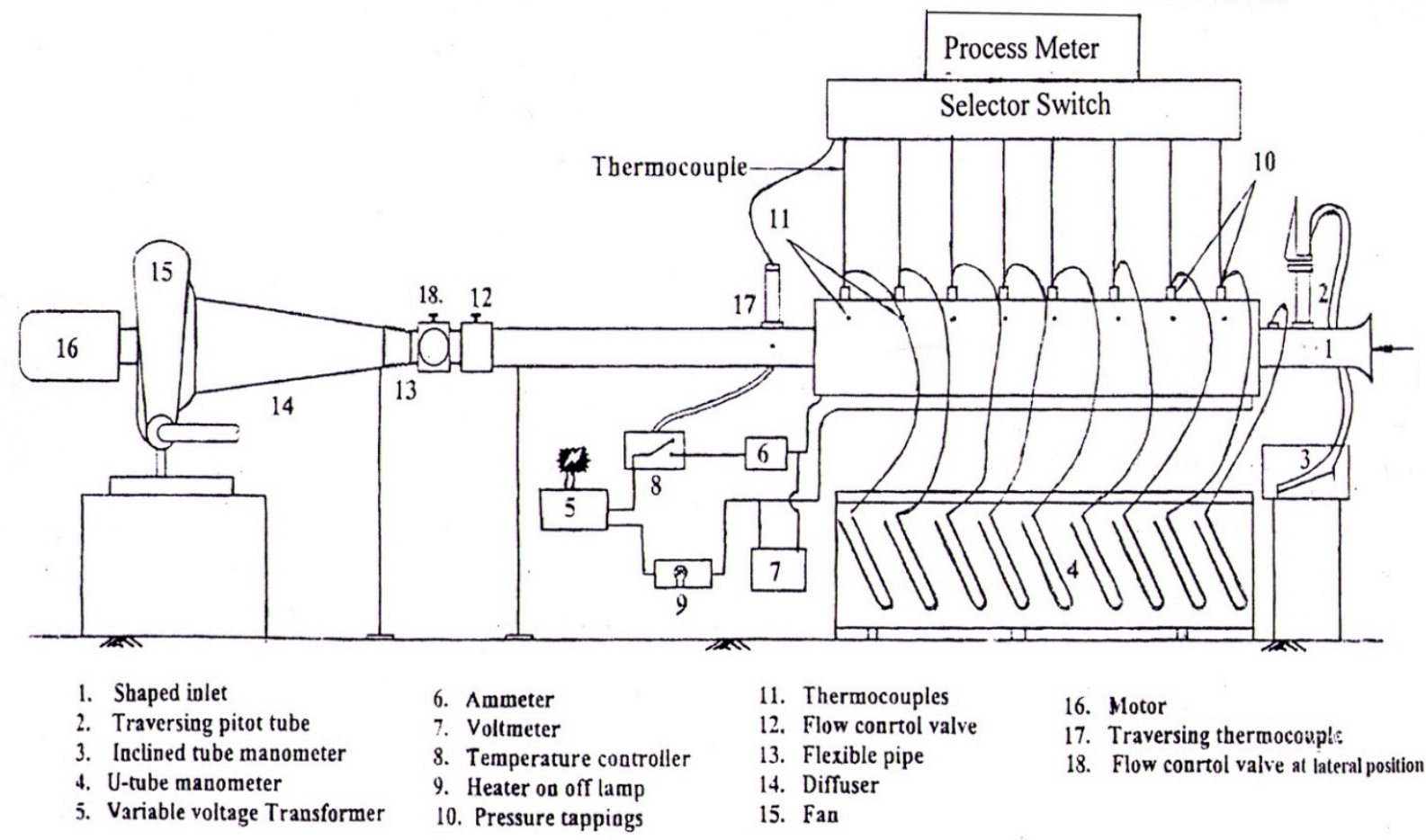

Figure 1: Schematic of the experimental set-up.

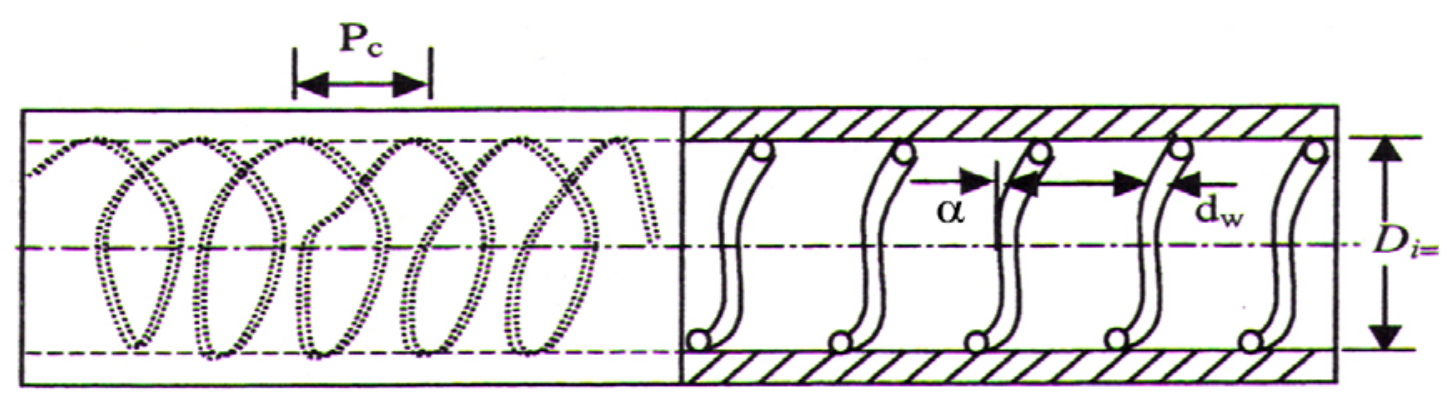

Figure 2: Cross-sectional view of the test section.

\section{EXPERIMENT}

\subsection{Experimental Facility}

Figure 1 shows the schematic drawing of the experimental apparatus to be used for analyzing the heat transfer enhancement. The experimental procedures could be better explained by describing the following section and system such as test section, air supply system, heating system and measurement system.

\subsubsection{Test Section}

The experimental procedure of the present study is the same as previously described in the experimental study of the turbulent heat transfer enhancement through a smooth tube and four tubes with wire-coil inserts at the Reynolds numbers ranging from 20000 to 45000 published in the report of Sarkar et al. [30]. The test section is prepared by a brass tube of $1500 \mathrm{~mm}$ length $(L)$ and $70 \mathrm{~mm}$ inside diameter $\left(D_{i}\right)$ where the wire coils of different pitches are inserted. The mild steel wire coil is made by tightly wrapping a coil of spring on a circular rod which is shown in Figure 2. The outside diameter of the wire coil is slightly larger than the inside diameter of the smooth tube so that the coil may be tightly fitted against the tube wall. The wire coil having a wire diameter $\left(d_{w}\right)$ of $3.25 \mathrm{~mm}$ is inserted into the smooth tube. After inserting the coil, the two halves of the smooth tubes are clamped and the pudding is pressed into the joint of the tube to prevent any leakage. The test section is wrapped at first with a mica sheet and then a glass-fiber tape before wrapping with Nichrome wire (which is used as an electric heater and the resistance of wire is of $0.249 \Omega / \mathrm{m}$ for smooth tube and of $0.739 \Omega / \mathrm{m}$ for coil-inserted tubes) spirally wound around the tube with $16 \mathrm{~mm}$ uniform spacing. Then again a mica sheet, a glass-fiber tape, a heat-insulating tape, and an asbestos tape are used sequentially over the wrapped Nichrome wire. The test section is installed in the test facility with the help 
of the bolted flanges, between which asbestos sheets are inserted to prevent the heat flow in the longitudinal direction. An unheated inlet section (sometimes called shaped inlet) casted from aluminum having the same diameter of test section is installed upstream of the test section. The shaped inlet having a length of $533 \mathrm{~mm}$ is made integral to avoid any flow disturbances at upstream of the test section in order to get a fully developed air flow in the test section.

\subsubsection{Air supply System}

In air supply system, a motor operated suction-type fan is fitted downstream of the test section so that any disturbance produced by the fan does not affect the flow on the test section. In order to minimize the head loss at the suction side, A $12^{\circ}$ diffuser of mild steel plate is fitted to the suction side of the fan. To arrest the vibration of the fan a flexible duct is installed between the inlet section of the fan and the gate valves. The gate valves which are known as the butterfly valves installed in order to control the flow rate of air. The butterfly valve consists of a metal circular disk or vane with its pivot axes at right angles to the direction of flow in the tube. To maintain the low turbulent flow at the required Reynolds numbers in the range of $R e=6000$ to 22000 for air inside the tube, two butterfly valves are used from which one value is fitted at the suction side of the tube and other valve is fitted at the lateral position of the main tube. Both valves are installed at the upstream of the flexible duct of the tube.

\subsubsection{Heating System}

In heating system, a Nichrome wire is wounded around the brass tube which provides a constant heat flux when it is connected to a power supply of $5 \mathrm{KVA}$ which are maintained with the help of a magnetic contactor and temperature controller. The temperature controller is fitted to sense the outlet air temperature by providing the signal in switching the heater off or on automatically. The on-off switch is provided mainly for the safety purpose during the excess heating of the test section. Heat input by Nichrome wire is kept constant during the experimental work and is evaluated by measuring the values of current and voltage supplied to the heating element.

\subsubsection{Measurement System}

In measurement system, the air flow velocity, the static pressure and the temperature are measured from the experiment. The mean velocity of air flow is measured at the inlet of the test section with the help of a traversing Pitot tube. In order to measure the static pressure, the pressure tappings arrangement are fitted so carefully that it just touches the inner surface of the test section and U-tube water manometers at an inclination of $30^{\circ}$ are also attached with the pressure tappings. To measure the temperatures of the wall and coil surfaces at the different axial locations of the test section, K-type thermocouples are used and connected with the selector switch and process meter. For smooth tube, 8 thermocouples are fitted at eight equally spaced axial locations of the test section to measure the wall temperatures. For coil-inserted tubes, sixteen thermocouples are fitted at eight locations. At each location, two thermocouples are fitted to measure the wall and the coil surface temperature of the test section.

\subsection{Experimental Procedure}

At first the fan is operated by pressing the switch as 'on' and later the fan is kept running for about five minutes to have the transient characteristics died out. The flow of air is set to a desired value and kept constant with the help of butterfly valves and the air flow is recorded with a traversing Pitot tube fitted at the inlet section of the tube. Then the electric heater is switched on and the electric power is adjusted (if necessary) with the help of a regulating transformer or variac. Steady state condition for temperature at different locations of the test section is defined by Gee and Webb [22] by two measurements. The variation in wall temperature is observed until constant values are attained, then the outlet air temperature is monitored. Steady state condition is attained when the outlet air temperature does not deviate over 10-15 minutes time during the process. At the steady state condition, thermocouple of K-type readings are recorded manually with the help of rotary selector switch and the readings include the air inlet and outlet temperatures, coil surface temperatures and tube wall temperatures. At the same time, manometer readings that indicate the pressure drops along the length of the test section are collected with the help of an inclined U-tube manometer. After each experimental run, the Reynolds number is changed with the help of butterfly valves for keeping a constant electrical power input. And after reaching the steady state condition, the readings of thermocouple, pressure tappings and traversing Pitot tube are recorded. In a similar fashion, the four test sections are arranged for four different pitches $\left(P_{c}=12,24,35\right.$ and $50 \mathrm{~mm}$ with corresponding helix angles, $\alpha=10^{\circ}, 20^{\circ}, 35^{\circ}$ and $45^{\circ}$ ) with a wire coil of mild steel with a diameter of $3.25 \mathrm{~mm}$.

\section{RESULTS AND DISCUSSIONS}

On the basis of the present experimental statistics by considering as much as $5 \%$ uncertainty of the different measured quantities [31], the fluid flow characteristics such as friction factors, pressure drops and pumping powers, and the heat transfer characteristics such as heat transfer coefficients, average Nusselt numbers and heat transfer effectiveness are analyzed and presented in the following section. In addition, a correlation is developed for the prediction of heat transfer coefficients both for smooth tube and tubes with wire-coil-inserts at low Reynolds numbers, and finally, a comparative study is also demonstrated between the present results and the predicted results obtained for the higher Reynolds number by Sarkar et al. [30]. 


\subsection{Friction Factor}

The average friction factors, $F_{i}$ for a smooth tube and four wire coil-inserted tubes against the Reynolds numbers, $R e$ are shown in Figure 3. As seen in the figure, the average friction factor gradually decreases with the increase of Reynolds number for the smooth tubes and the tubes with wire-coil inserts. The reason behind such a decreasing trend of friction factor is that at higher Reynolds number, a thin hydrodynamic boundary layer may be formed which causes a minimum value of the friction factors. It is also depicted that the value of friction factors for wire coil-inserted tubes becomes higher than that of the smooth tube and the average friction factor for the tube with a higher helix angles become lower than that of the tube with a lower helix angle. This fact implies that at a lower value of Reynolds number corresponding to lower flow rate, air just passes over the wire coil and the presence of small vortices behind the wire coil results an increasing trend in the friction factor. However, as the flow rate is increased, a secondary flow and hence some turbulences are induced in the flowing fluid due to the presence of a wire coil, which also provides an increasing trend in the higher values of pressure drops. Again, the average friction factor increases with the decrease of the helix angle due to the higher vortices generated behind the wire coils and this similar behavior is also shown for the profiles of the friction factors at higher Reynolds numbers (Sarkar et al., [30]). It is noted that the local friction factor gets higher value near the entrance region, then sharply falls up to $X / L=0.3$, after which it remains almost constant specifying the fully developed flow (not shown in Figure). The higher friction factor at the entrance region may be attributed to presence of asbestos plate between the sharp inlet and test section. It can be indicated that the average friction factor for the tubes with wire-coil-inserts at low Reynolds numbers increases as much as 3.5 times higher than that of the smooth tube.

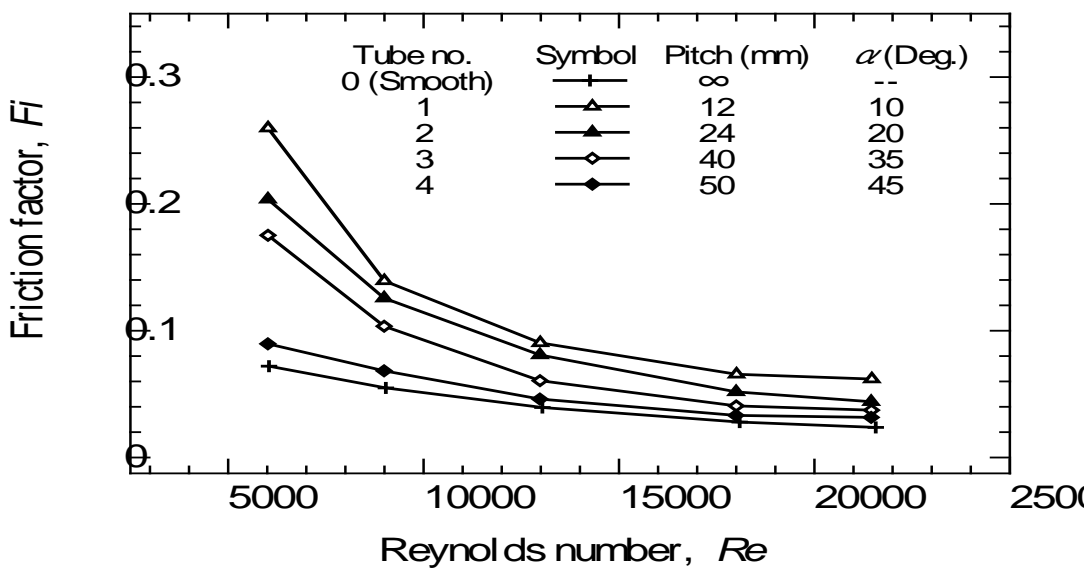

Figure 3: Variation of average friction factor against Reynolds number for smooth tube and wire-coil inserted tubes.

\subsection{Pressure Drop}

Figure 4 shows the average pressure drops, $\Delta P$ for a smooth tube and the tubes with wire-coil-inserts against Reynolds numbers, $R e$. It can be seen from the Figure that the average pressure drop gradually increases with the increase of Reynolds number for all tubes. Also, the profiles of the average pressure drops for the coil-inserted tubes becomes higher than that of the smooth tube and the pressure drops for a tube with a lower helix angle become higher than that of the tube with the higher helix angle in analogy with the profiles of an average friction factors as shown in Figure 3.

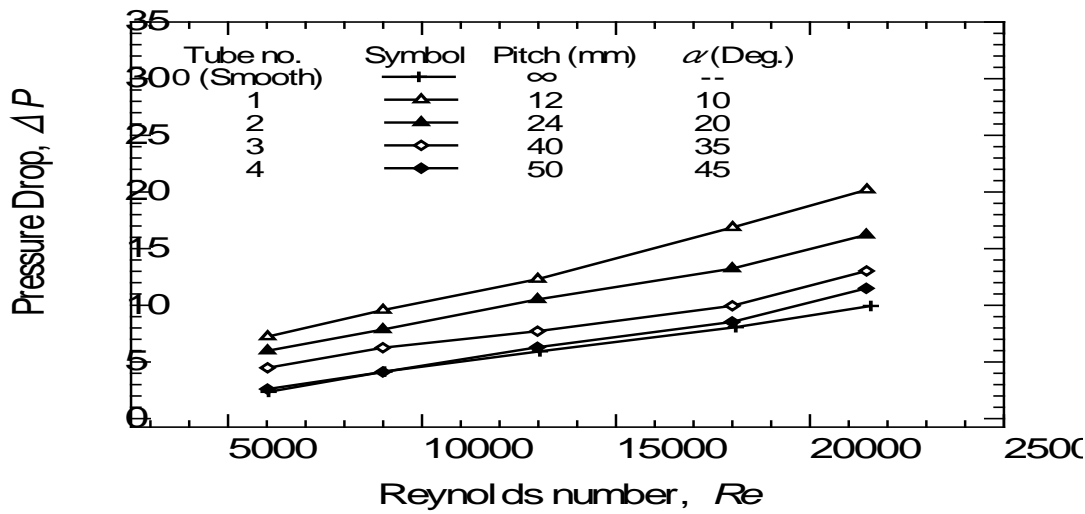

Figure 4: Variation of average pressure drop against Reynolds number for smooth tube and wire-coil inserted tubes. 


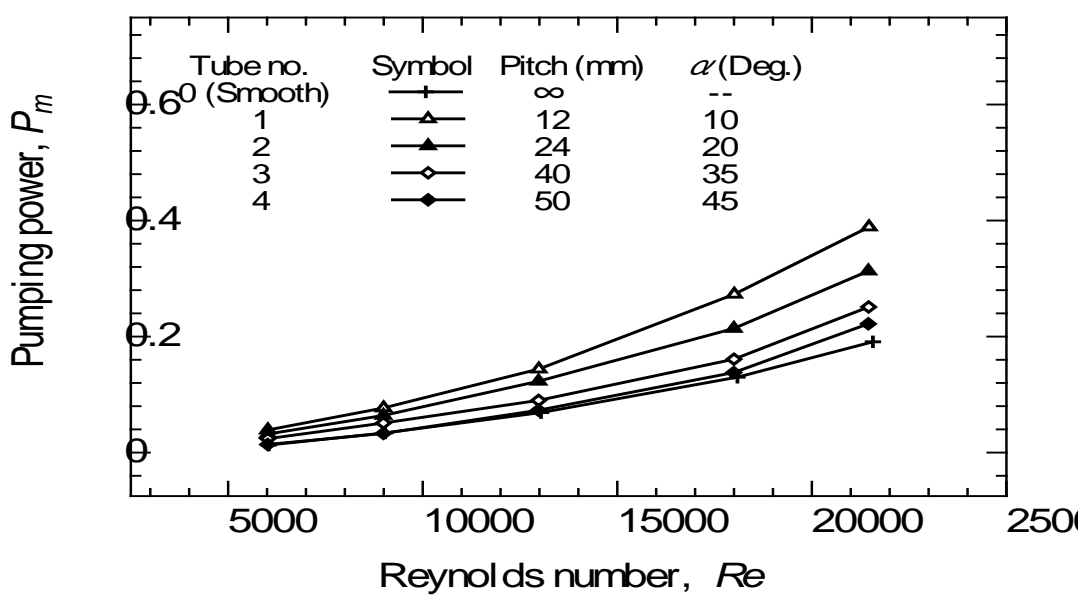

Figure 5: Variation of average pumping power against Reynolds number for smooth tube and wire-coil inserted tubes.

\subsection{Pumping Power}

The variation of the pumping powers, $P_{m}$ both for the smooth tube and the tubes with wire-coil inserts are shown against Reynolds numbers, $R e$ in Figure 5 . As seen in the Figure, the pumping power for all tubes increases as the Reynolds number increases and the pumping power of wire-coil inserted tubes become higher than that of the smooth tube. The presence of small vortices behind the wire coil is responsible for higher pressure drops as previously described in the friction factor shown in Figure 3, and consequently the pumping power increases. It is noted that the required pumping power for the tubes with wire-coil-inserts at low Reynolds numbers varies as much as two times higher than that of the smooth tube.

\subsection{Average Heat Transfer Coefficients}

Figure 6 depicts the variation of average heat transfer coefficients, $h$ against the Reynolds number, Re for the smooth tube and the tubes with wire-coil inserts. It can be seen from the Figure that the average heat transfer coefficient increases with the Reynolds numbers for all tubes. The local heat transfer coefficient is large at the entrance of the test section due to the development of thermal boundary layer and the coefficient decreases sharply along the axial distance up to $X / L=0.3$, after which it remains nearly constant demonstrating the fully-developed thermal boundary layer (not shown in Figure). It can be also seen that the average heat transfer coefficient for the tubes with wire-coilinserts becomes higher than that of the smooth tube and the coefficient for a higher helix angles corresponds to a higher value in comparison with those of the tube with a lower helix angle. It can be noted that the average heat transfer coefficient for the tubes with wire-coil-inserts increases as much as two-fold as compared to that of the smooth tube for a comparable Reynolds numbers.

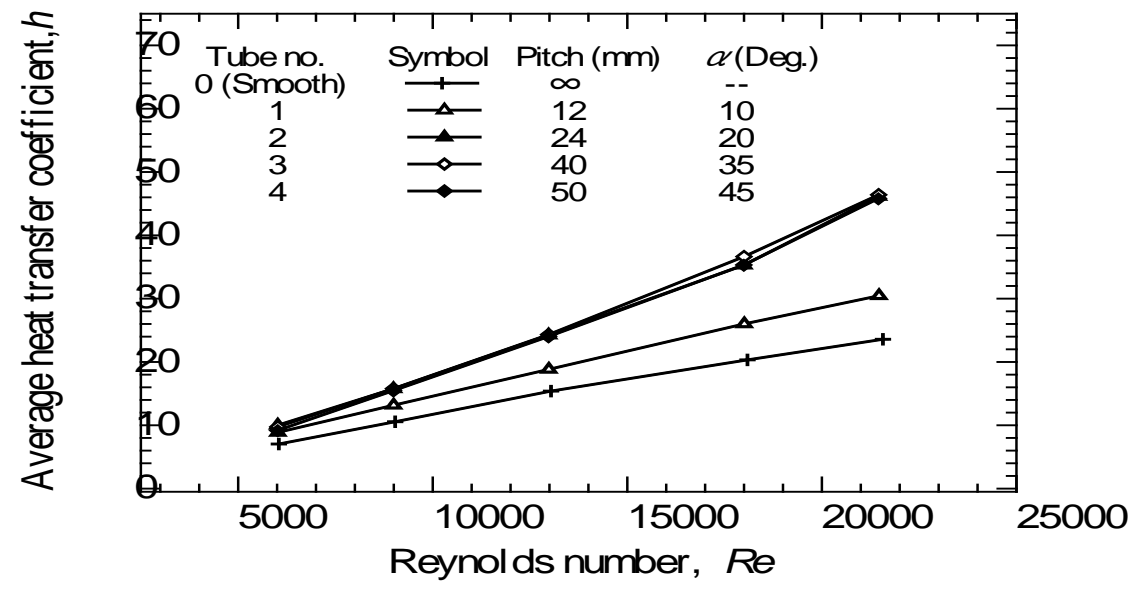

Figure 6: Variation of average heat transfer coefficients against Reynolds number for smooth tube and wire-coil inserted tubes. 


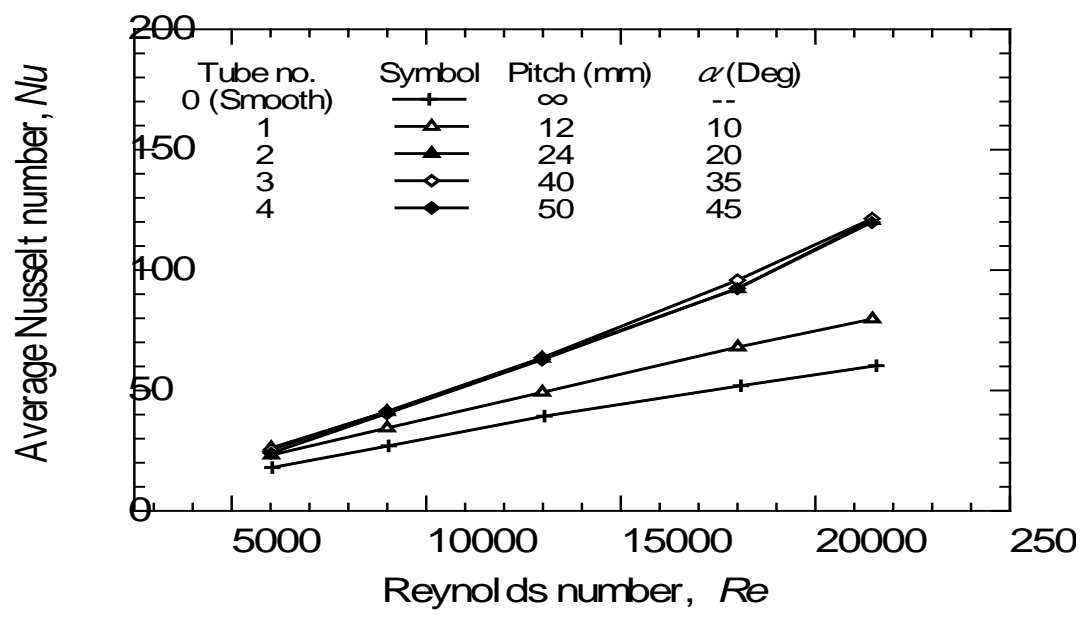

Figure 7: Variation of average Nusselt number against Reynolds number for smooth tube and wire-coil inserted tubes.

\subsection{Average Nusselt Number}

The variation of the average Nusselt numbers, $\mathrm{Nu}$ both for the smooth tube and the tubes with wire-coil inserts are shown against Reynolds numbers, $R e$ in Figure 7. As shown in the Figure, the average Nusselt number increases with the increase of Reynolds number and the average Nusselt numbers for wire coil-inserted tubes become higher as compared with that of the smooth tube. It can be seen from the figure that the average Nusselt numbers for a tube with higher helix angle become higher than that of the tube with lower helix angle. The local Nusselt number is large in the entrance region due to the development of thermal boundary layer with the entrance section at the leading edge and then gradually decreases up to a certain point $(X / L=0.3)$, after which the thermal boundary layer could be considered fully developed as described previously. The reason behind the higher local Nusselt number with Reynolds number is that a higher flow rate results in an increment of local Nusselt number at tube surface (not shown in Figure).

\subsection{Effectiveness}

The analysis of the heat transfer effectiveness, $e$ is of very importance for many engineering applications. The heat transfer effectiveness both for smooth tube and wire-coil inserted tubes is considered by considering the constant wall temperature and may be defined as $e=\left(T_{b o}-T_{b i}\right) /\left(T_{\text {wavg }}-T_{b i}\right)$. The symbols $T_{b o}, T_{b i}$ represent the bulk temperature based on outside diameter and inside diameter, respectively, and $T_{\text {wavg }}$ represents average wall temperature of coil surface. Figure 8 depicts the variation of average heat transfer effectiveness both for smooth tube and the tubes with wire-coil inserts as a function of Reynolds number, $R e$. It can be seen from the Figure that the heat transfer effectiveness increases with the increase of Reynolds number. It can be indicated that for a comparable Reynolds number, the heat transfer effectiveness for wire-coil inserted tubes varies as much as 1.25 times higher than that of the smooth tube.

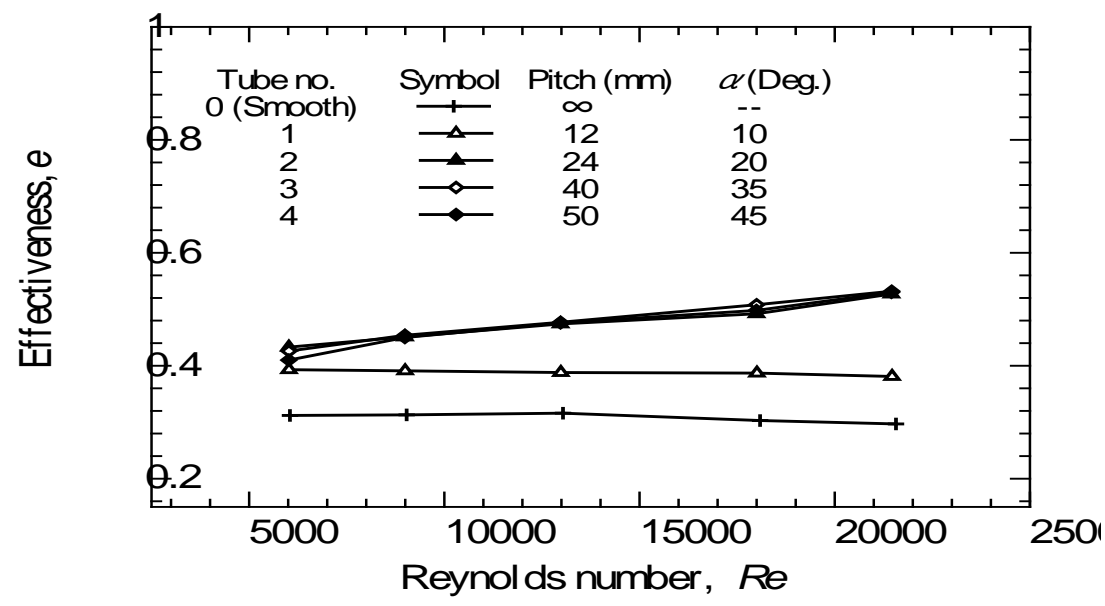

Figure 8: Variation of average effectiveness against Reynolds number for smooth tube and wire-coil inserted tubes. 


\subsection{Prediction of Heat Transfer Coefficients}

As mentioned above, the variation of an average heat transfer coefficient is a function of the Reynolds number for both smooth tube and wire-coil inserted tubes. It is evident that the Nusselt number for smooth tube and with wirecoil inserted tubes is a function of the Reynolds number and the helix angle of the coil. These may be correlated by the equation as follows.

$$
N u=C \operatorname{Re}^{m} \operatorname{Pr} 0.33
$$

The slope of the straight line for Equation (1) is obtained from the graph plotted on $\left(\mathrm{Nu} / \mathrm{Pr} \mathrm{r}^{0.33}\right)$ vs. Re as shown in Figure 9. As seen in Figure 9, the average Nusselt number representing as $N u / P P^{0.33}$ increases with Reynolds number in a similar way as shown in Figure 7. The coefficient $C$ of Equation (1) is plotted against tana in Figure 10. As seen in Figure 10, the value of $C$ varies with tan $\alpha$, where the values of tan $\alpha$ represent the tangent values of the helix angle of the wire coil, and hence, the variation of $C$ with $\tan \alpha$ can be represented by the relation as follows.

$$
C=0.0071(\tan \alpha)^{2}-0.0124 \tan \alpha+0.0057
$$

On the other hand, the exponent $m$ of Equation (1) is plotted against tan $\alpha$ in Figure 11. As seen in Figure 11, the value of $m$ varies with $\tan \alpha$, where the values of $\tan \alpha$ represent the tangent values of the helix angle of the wire coil as described previously, and hence, the variation of $m$ with tan $\alpha$ can be represented by the relation as follows.

$$
m=-0.3971(\tan \alpha)^{2}+0.6994 \tan \alpha+0.9286
$$

The final correlation of the Nusselt number with the Reynolds number and helix angles can be predicted as follows.

$$
N u=\left[0.0071(\tan \alpha)^{2}-0.0124 \tan \alpha+0.0057\right] \times R e^{[-0.3971(\tan \alpha) 2+0.6994 \tan \alpha+0.9286]} \times P P^{0.33}
$$

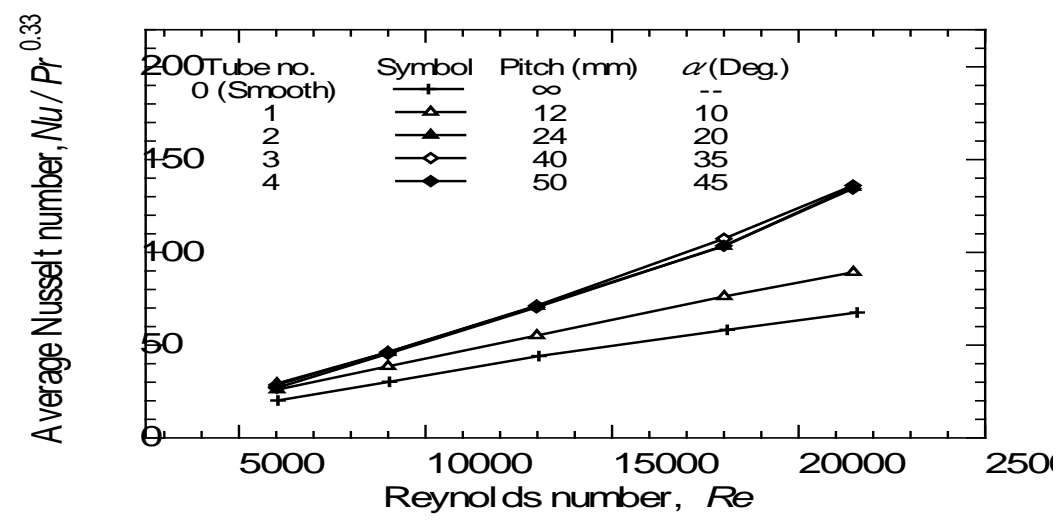

Figure 9: Variation of average Nusselt number $\left(\mathrm{Nu} / \mathrm{Pr}{ }^{0.33}\right)$ against Reynolds number for smooth tube and wire-coil inserted tubes.

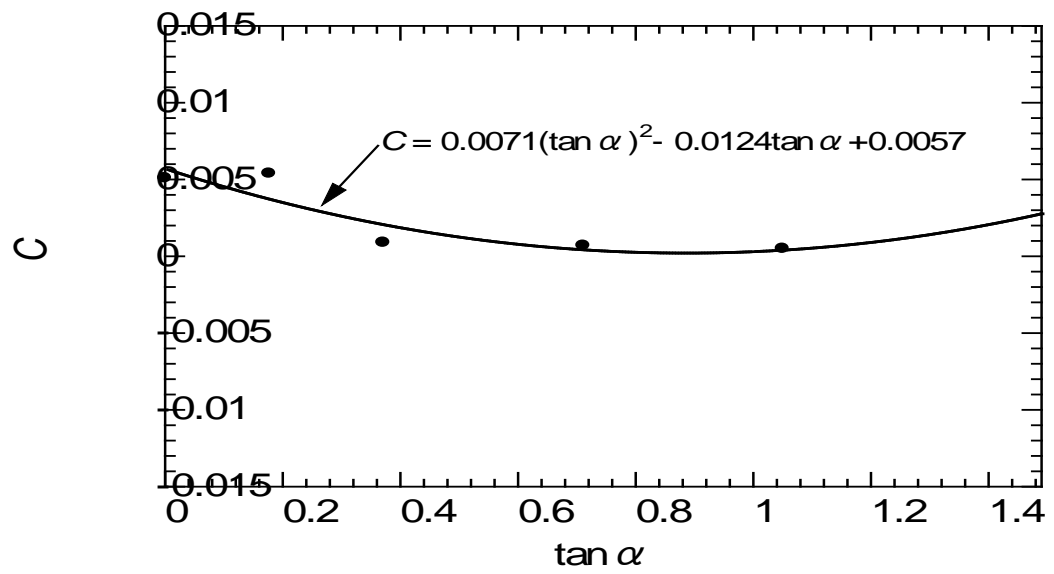

Figure 10: Variation of $c$ against $\tan \alpha$ for smooth tube and wire-coil inserted tubes. 
The average heat transfer coefficients found in the present experimental study are predicted by applying the correlation developed-above in Equation (4). Figures 12-16 show the prediction of the average Nusselt numbers both for the smooth tube and the tubes with wire-coil inserts along, and they are compared with the predicted statistics of the heat transfer coefficients for higher Reynolds numbers (Sarkar et al., [30]).

Figure 12 demonstrates the predicted heat transfer coefficients represented by average Nusselt number, Nu against Reynolds number, Re for smooth tube. As can be seen in Figure 12, the average Nusselt number predicted by Equation (4) corresponds well with the present experimental results for smooth tube for low Reynolds number. The predicted average Nusselt number also agrees well with the values predicted by Sarkar et al., [30] for higher Reynolds number. The predicted heat transfer coefficients represented by average Nusselt number, Nu against Reynolds number, Re for wire-coil-inserted tube (Pitch, $P_{c}=12 \mathrm{~mm}$, helix angle, $\alpha=10^{\circ}$ ) is depicted in Figure 13. As can be seen in Figure 13, the average Nusselt number predicted by Equation (4) corresponds relatively well with the present experimental results for wire-coil-inserted tube for low Reynolds number. However, the predicted average Nusselt number agrees very well with the values predicted by Sarkar et al., [30] for higher Reynolds number. Figure 14 demonstrates the predicted heat transfer coefficients represented by average Nusselt number, Nu against Reynolds number, Re for wirecoil-inserted tube (Pitch, $P_{c}=24 \mathrm{~mm}$, helix angle, $\alpha=20^{\circ}$ ). As can be seen in Figure 14, the average Nusselt number predicted by Equation (4) does not correspond well with the present experimental results for wire-coil-inserted tube for low Reynolds number. However, the predicted average Nusselt number does not agree with the values predicted by Sarkar et al., [30] for higher Reynolds number. Figure 15 demonstrates the predicted heat transfer coefficients represented by average Nusselt number, Nu against Reynolds number, Re for wire-coil-inserted tube (Pitch, $P_{c}=40$ $\mathrm{mm}$, helix angle, $\alpha=35^{\circ}$ ). As can be seen in Figure 15, the average Nusselt number predicted by Equation (4) also does not correspond well with the present experimental results for wire-coil-inserted tube for low Reynolds number. However, the predicted average Nusselt number does not agree with the values predicted by Sarkar et al., [30] for higher Reynolds number.

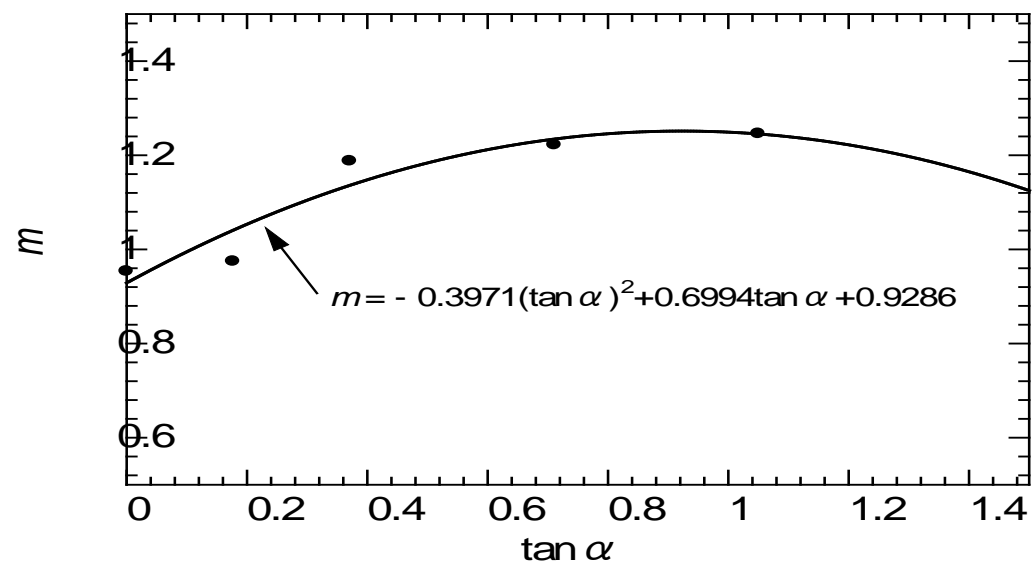

Figure 11: Variation of $m$ against $\tan \alpha$ for smooth tube and wire-coil inserted tubes.

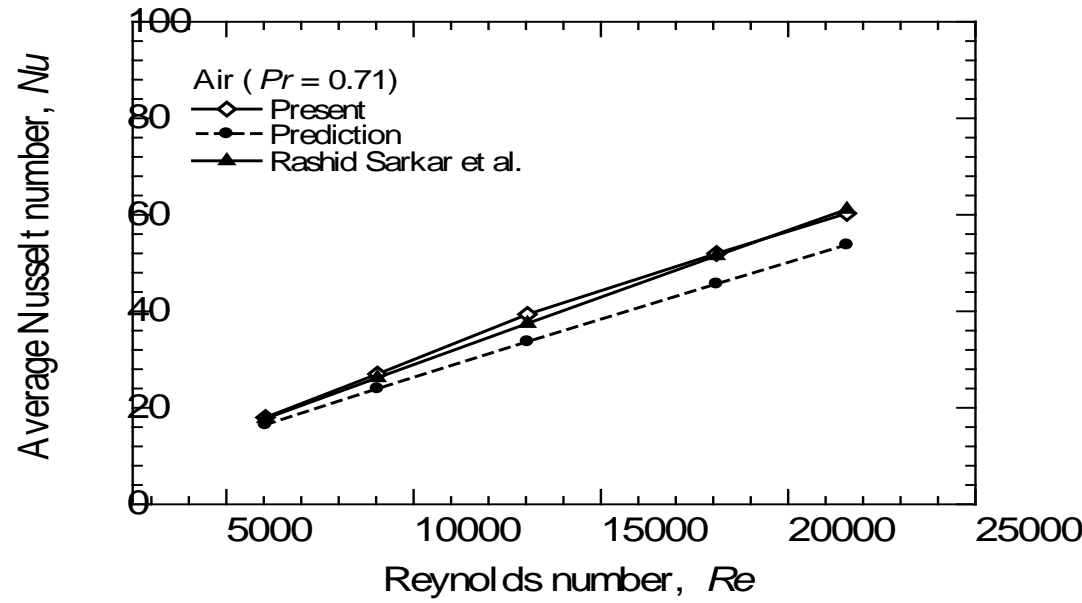

Figure 12: Prediction of heat transfer coefficients for smooth tube. 


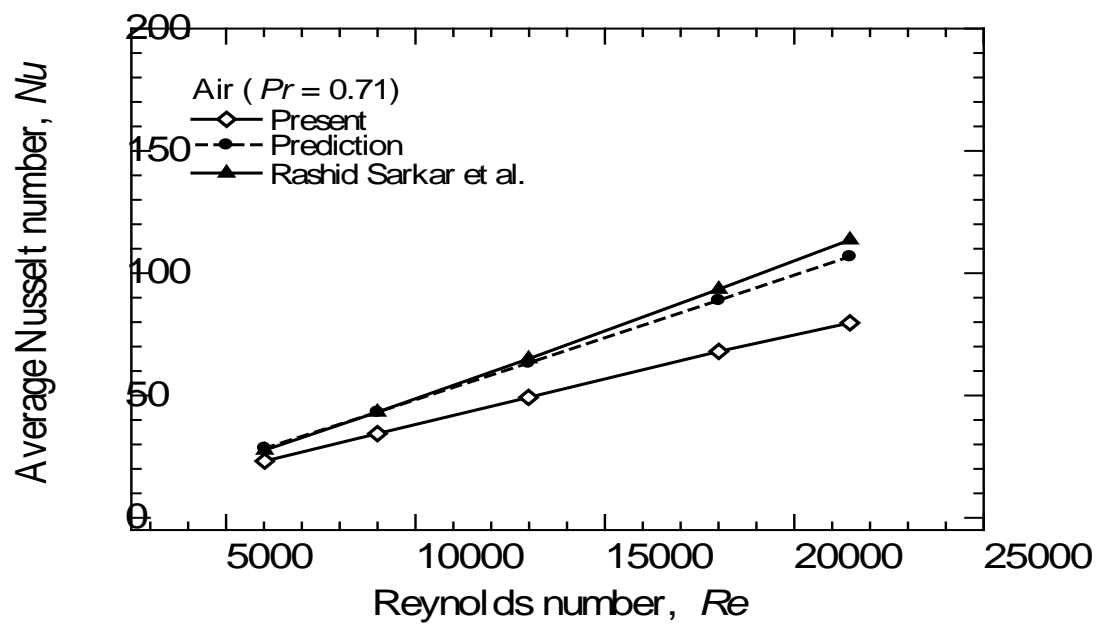

Figure 13: Prediction of heat transfer coefficients for wire-coil inserted tube (Pitch, $P_{c}=12 \mathrm{~mm}$, helix angles, $\alpha=10^{\circ}$ ).

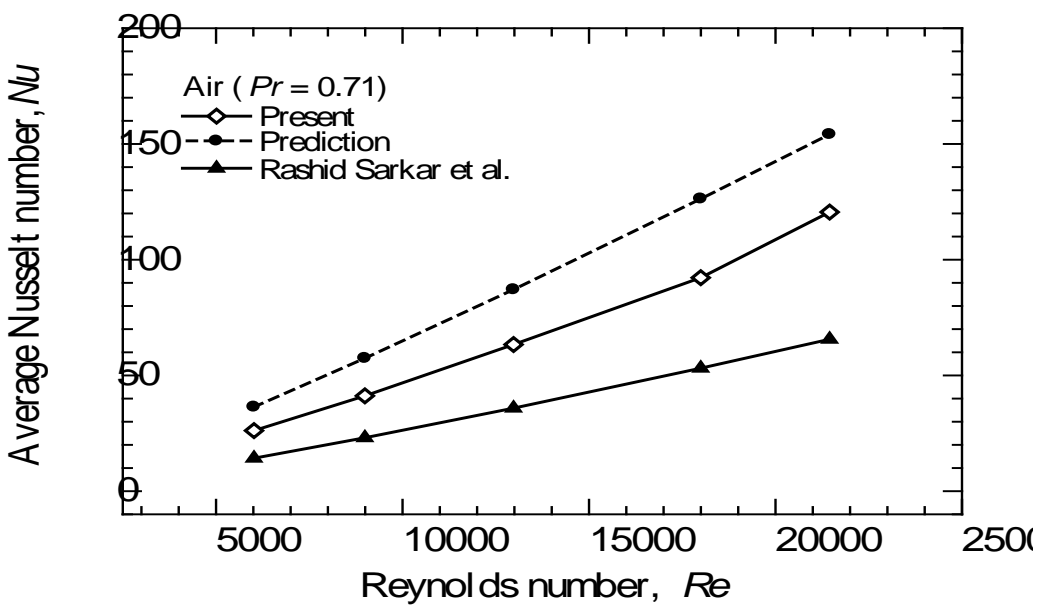

Figure 14: Prediction of heat transfer coefficients for wire-coil inserted tube (Pitch, $P_{c}=24 \mathrm{~mm}$, helix angles, $\alpha=20^{\circ}$ ).

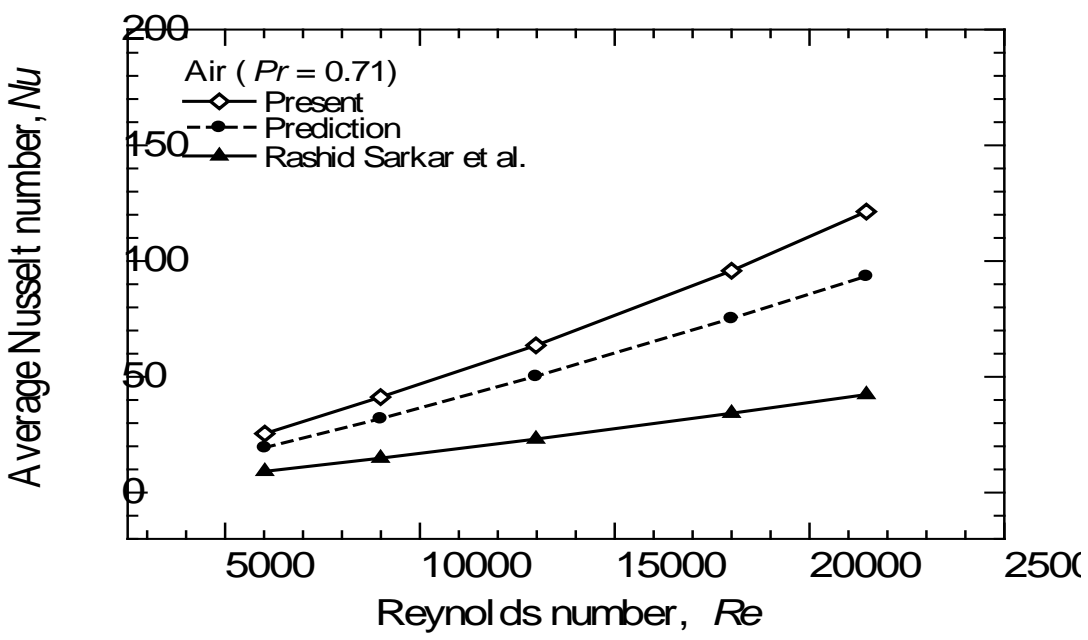

Figure 15: Prediction of heat transfer coefficients for wire-coil inserted tube (Pitch, $P_{c}=40 \mathrm{~mm}$, helix angles, $\alpha=35^{\circ}$ ). 


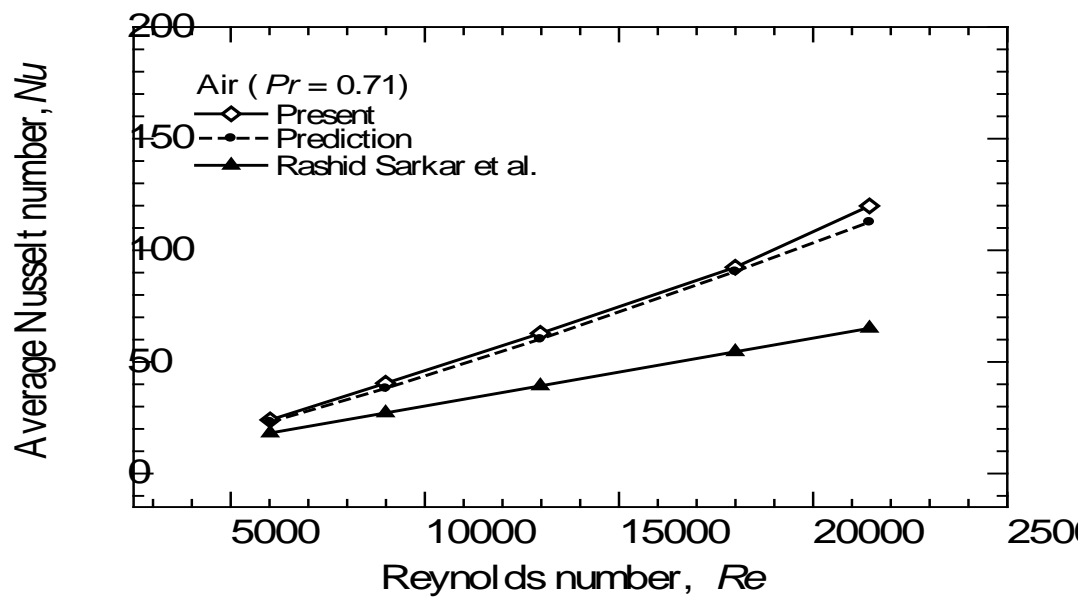

Figure 16: Prediction of heat transfer coefficients for wire-coil inserted tube (Pitch, $P_{c}=50 \mathrm{~mm}$, helix angles, $\alpha=45^{\circ}$ ).

The predicted heat transfer coefficients represented by average Nusselt number, Nu against Reynolds number, Re for wire-coil-inserted tube (Pitch, $P_{c}=50 \mathrm{~mm}$, helix angle, $\alpha=45^{\circ}$ ) is depicted in Figure 16. As can be seen in Figure 16, the average Nusselt number predicted by Equation (4) corresponds very well with the present experimental results for wire-coil-inserted tube for low Reynolds number. However, the predicted average Nusselt number does not agree with the values predicted by Sarkar et al., [30] for higher Reynolds number.

It can be seen from those figures that the average Nusselt number predicted by Equation (4) agrees relatively well with the experimental results both for smooth tube and wire-coil inserted tubes except for the tubes with helix angles of $\alpha=20^{\circ}$ and $35^{\circ}$.

\section{CONCLUSIONS}

An experimental investigation has been conducted to study the heat transfer enhancement in turbulent flow of air through one smooth tube and four wire-coil inserted tubes. The study has revealed that the wire-coil inserted tubes would enhance a heat transfer rate at the cost of increased pumping power. The results of the present experimental study may be summarized as follows.

- For comparable Reynolds numbers, the friction factor for the wire-coil inserted tubes becomes as much as fourfolds higher than those observed in the smooth tube. The local friction factor is high near the inlet section and drops gradually to the fully developed flow.

- The average heat transfer coefficient for tube with wire-coil-inserts increases as much as two-fold in comparison with that of the smooth tube for similar flow condition.

- For comparable Reynolds numbers, the heat transfer effectiveness for the wire-coil inserted tubes increases as much as 1.25 folds than that of the smooth tube.

\section{ACKNOWLEDGEMENT}

The authors wish to express their gratitude to former Professor A. M. Azizul Hoq of the Department of Mechanical Engineering, Bangladesh University of Engineering and Technology (BUET), for his continuous support and important suggestions in the modifications of the experimental setup during the present work. Also, the authors are thankful to Mr. M. Zaidul Islam of the Department of Mechanical Engineering, BUET, for his cooperation.

\section{REFERENCE}

1. Shailendhra, K., \& Anjali Devi, S. P. (2011). On the enhanced heat transfer in the oscillatory flow of liquid metals. Journal of Applied Fluid Mechanics, I. 4, 57-62.

2. He, Y., Zeng, H., Zhang, Q., Tang, Y., \& Zhang, J. (2012). Analysis of enhanced heat transfer performance through duct with constant wall temperature. Journal of Thermodynamics and Heat Transfer, 26(3), 472-475.

3. Jafari Nasr, M. R., Habibi Khalaj, A., \& Mozaffari, S. H. (2010). Modeling of heat transfer enhancement by wire coil inserts using artificial neural network analysis. Journal of Applied Thermal Engineering, 30, 143-151.

4. Gunes, S., Ozceyhan, V., \& Buyukalaca, O., (2010). Heat transfer enhancement in a tube with equilateral triangle cross sectioned coiled wire inserts. Experimental Thermal and Fluid Science, 34, 684-691. 
5. Garcia, A., Vicente, P. G., \& Viedma, A. (2005). Experimental study of heat transfer enhancement with wire coil inserts in laminar-transition-turbulent regimes at different Prandtl numbers. International journal of Heat and Mass Transfer, 48, 4640-4651.

6. Uttarwar, S. B., \& Rao, M. R. (1985). Augmentation of laminar flow heat transfer in tubes by means of wire coil inserts. Journal of Heat Transfer, 105, 930-935.

7. Edwards, D. P., \& Jensen, M. K. (1994). Pressure drop and heat transfer predictions of turbulent flow in longitudinal finned tubes. Advances in Enhanced Heat Transfer, ASME HTD, 287, 17-30.

8. Mafiz, H., Huq, A. M. A., \& Rahman, M. M. (1996). An experimental study of heat transfer in an internally finned tube. Proceedings of ASME Heat Transfer Division, 2, 211-217.

9. Islam, M. A., \& Mozumder, A. K. (2009). Forced convection heat transfer performance of an internally finned tube. Journal of Mechanical Engineering Transaction, IEB, ME 40(1), 54-62.

10. Eiamsa-ard, S., Wongcharee, K., Eiamsa-ard, P., Thiangpong, C. (2010). Heat transfer enhancement in a tube using delta-winglet twisted tape inserts, Applied Thermal Engineering, 30, 310-318.

11. Date, A. W. (1974). Prediction of fully-developed flow in a tube containing a twisted tape. International Journal of Heat and Mass Transfer. 17, 845-859.

12. Hong, S. W., \& Bergles A. E. (1976). Augmentation of laminar flow heat transfer in tubes by means twistedtape inserts. ASME Journal of Heat Transfer, 98, 251-56.

13. Marner, W. J., \& Bergles A. E. (1978). Augmentation of tube side laminar flow heat transfer in tubes by means twisted-tape inserts, static mixer inserts, and internally finned tubes. Proceedings of 6th International Heat Transfer Conference, Hemisphere Publishing, Washington DC, 583-588.

14. Van Rooyen, R. S., \& Kroger D. G. (1978). Laminar flow heat transfer in internally finned tubes with twistedtape-inserts. Proceedings of 6th International Heat Transfer Conference, Toronto, Canada.

15. Plessis, J. P., \& Kroger, D. G. (1987). Heat transfer correlation for thermally developing laminar flow in a smooth tube with a twisted-tape insert. International Journal of Heat and Mass Transfer, 30(3), 509-515.

16. Gupte, N. S., \& Date, A. W. (1989). Friction and heat transfer characteristics of helical turbulent air flow in annulis. Journal of Heat Transfer, 111, 337-344.

17. Manglik, R. M., \& Bergles, A. F. (1993). Heat transfer and pressure drop correlations for twisted-tape inserts in isothermal tubes: part 1- laminar flows. Journal of Heat Transfer, 115, 881-889.

18. Saha, S. K., \& Dutta, A. (2001). Thermohydraulic study of laminar swirl flow through a circular tube fitted with twisted tapes. ASME Journal of Heat Transfer, 123, 417-425.

19. Wang, S., Guo, Z. Y., \& Li, Z. X. (2000). Heat transfer enhancement by using metallic filament insert in channel flow. International Journal Heat and Mass Transfer, 44, 1373-1378.

20. Mergerlin, F. E., Murphy, R. W., \& Bergles, A. E. (1974). Augmentation of heat transfer in tubes by means of mesh and brush inserts. Journal of Heat Transfer, 96, 145-151.

21. Saha, S. K., \& Langille, P. (2002). Heat transfer and pressure drop characteristics of laminar flow through a circular tube with longitudinal strip inserts under uniform wall heat flux, ASME Journal of Heat Transfer, 124, 421-430.

22. Gee, D. L., \& Webb, R. L. (1980). Forced convection heat transfer in helically rib-roughened tubes, International of Journal of Heat and Mass Transfer, 23, 1127-1136.

23. Patankar, S. V., Ivanovic, M., \& Sparrow, E. M. (1989). Analysis of turbulent flow heat transfer in internally finned tube and annuli, Journal Heat Transfer, 101, 29-37.

24. Prakash, C., \& Patankar, S. V. (1981). Combined free and forced convection in vertical tubes with radial internal fins, Journal of Heat Transfer, 103, 566-672.

25. Chowdhury, D., \& Patankar, S. V. (1985). Analysis of Developing Laminar Flow and Heat Transfer in Tubes with Radial Internal Fins, Proc. ASME National Heat Transfer Conf., 57-63.

26. Prakash, C., Liu, Y. D. (1985). Analysis of laminar flow and heat transfer in the entrance region of an internally finned circular duct, Journal of Heat Transfer, 107, 84-91.

27. Sethumadhavan, R., Rao, R. M. (1983). Turbulent flow heat transfer and fluid friction in helical-wire-coilinserted tubes, International Journal Heat Mass Transfer, 26, 1833-1845.

28. Vahidifar, S., \& Kahrom, M. (2015). Experimental study of heat transfer enhancement in a heated tube caused by wire-coils and rings, Journal of Applied Fluid Mechanics, 8(4), 885-892.

29. Garcia, A., Solano, J. P., Vicente, P. G., \& Viedma, A. (2007). Enhancement of laminar and transitional flow heat transfer in tubes by means of wire coil inserts, International Journal of Heat and Mass Transfer, 50, 31763189.

30. Sarkar, M. A. R., Islam, M. Z., \& Islam, M. A., (2005). Heat transfer in turbulent flow through tube with wirecoil inserts. Journal of Enhanced Heat Transfer, 12(4), 385-394.

31. Kline, S. J., \& McClintock, F. A. (1953). Describing uncertainties in single-sample experiments, Mechanical Engineering, 3. 